
\title{
25 Research Square \\ Depth-dependent changes in nitrogen fixation and related organisms in mangrove sediments
}

\section{Zhiwen Luo}

Qiuping Zhong

Xingguo Han

Ruiwen Hu

Xingyu Liu

Wenjun Xu

Yongjie Wu

Weiming Huang

Zhengyuan Zhou

Wei Zhuang

Qingyun Yan

Zhili He

Cheng Wang

\section{Video Byte}

Keywords: Microbiome, diazotroph, nitrogen fixation rate, NFR, depth-dependent variability, nitrogen cycling, microbiome, nitrogen, nitrogen-fixing prokaryote, mangrove, sediment, nitrogen fixation, N2 fixation, nitrification, denitrification, diazotrophic, metagenomic, mixotroph, facultative anaerobe, sediment salinity, sediment core

Posted Date: March 1st, 2022

DOI: https://doi.org/10.21203/rs.3.rs-1405873/v1

License: (c) (i) This work is licensed under a Creative Commons Attribution 4.0 International License. Read Full License 


\section{Abstract}

Diazotrophs, microorganisms that "fix" atmospheric nitrogen into ammonia that plants can use, are important members of mangrove ecosystems. Diazotrophic community structure and nitrogen fixation rates are strongly regulated by the environment, but how they change with sediment depth remains unclear. To find out, a new study investigated biological nitrogen fixation in sediment cores taken from a mangrove ecosystem in China. The results showed that diazotroph diversity decreased with depth, and salinity was the main factor that influenced the diazotrophic community structure. Communities above vs. below $50 \mathrm{~cm}$ were markedly different. In sediments shallower than $50 \mathrm{~cm}$, Anaeromyxobacter, Rubrivivax, Methylocystis, Dickeya and Methylomonas dominated, while Agrobacterium and Azotobacter dominated from 50 to $100 \mathrm{~cm}$. The nitrogen fixation rate and the abundance of nitrogen fixation genes increased with depth, while the abundance of genes related to nitrification and denitrification decreased. Metagenomic analyses revealed that deep-sediment diazotrophs could survive in low-oxygen environments and obtain nutrients from various sources. Although additional research is needed, the results provide new insights into nitrogen fixation in mangrove sediments and reveal depth-dependent changes that may help ensure nitrogen availability in deep mangrove sediments. 